\title{
Prediction of position-dependent stability lobes based on reduced virtual model
}

\author{
Filip $\mathrm{Ksica}^{1, *}$, and Zdenek Hadas ${ }^{1}$ \\ ${ }^{1}$ Brno University of Technology, Faculty of Mechanical Engineering, Technicka 2896/2, 61669 Brno, \\ Czech Republic
}

\begin{abstract}
The stability of a machining process is directly affected by the dynamic response between the tool and the workpiece. However, as the tool moves along the path, the dynamic stiffness of the machine tool changes. To determine the position-dependent dynamic stiffness accurately, a computationally efficient methodology based on a complex virtual model is presented. The virtual model is assembled using Finite Element Method and is effectively reduced via Component Mode Synthesis and transformation to a State-Space Multi-Input-Multi-Output system. Combination of these techniques allows time-efficient response simulations with significantly less computational effort than the conventional full Finite Element models. Furthermore, they describe the behaviour of the complex structure more accurately opposed to the commonly used models based on a simple 1 Degree-of-Freedom systems. The reduced model is used to simulate dynamic response of the structure to a cutting force during operation. A response is measured on an existing machine to modify the virtual model by incorporating fuzzy parameters, such as damping. The stability regions are calculated for variable positions, resulting in position-dependent lobe diagrams. The presented approach can be used to create a map of stable zones to predict and prevent unstable behaviour during operation.
\end{abstract}

\section{Introduction}

Present machine tool development requires time-efficient analyses of the structural dynamics to determine the stability of the cutting processes. Machine tool's behaviour during operation is directly affected by the dynamic stiffness between the tool and the workpiece. Various operating parameters, such as depth of cut and spindle speed, affect the stability of the cutting process and the presence of unstable chatter vibrations $[1,2]$. Furthermore, the dynamic stiffness changes as the tool moves along the path within the work volume, resulting in varying structural vibrations. Up to date, problems related to unstable behaviour caused by insufficient dynamic stiffness have been solved mostly on existing machines by response measurements and compensations [3] or very simple analytical models based on one or two Degree-of-Freedom (DOF) models with spring-damper elements [4]. The parameters of such models are usually determined by impact hammer measurements. For machines with considerable number of modes within observed frequency spectrum, a 1 DOF representation

\footnotetext{
* Corresponding author:Filip.Ksica@,vutbr.cz
} 
of each axis is relatively insufficient, as it cannot describe complex dynamic behaviour. In order to create sufficient models during the design process without the necessity to measure position-varying dynamic behaviour of the machine tool [5], an approach based on reduced virtual model [6] is proposed.

\section{Methods for virtual model assembly}

Stability lobe diagrams are used to derive machining parameters, such as depth of cut and spindle speed, to assure the machine tool is working in a stable area [7]. To construct them, a Frequency Response Function (FRF) between cutting force and tool tip displacement has to be determined. The FRF can be obtained either experimentally or via response simulations on a virtual model. Because the approach proposed in this paper focuses on the latter option, a complex virtual model has to be created to substitute an existing machine with sufficient accuracy. This paper uses a vertical mill as a model object, and only vertical motion of the headstock (axis Z) is considered. Including all three axes of the vertical mill would introduce two additional dimensions and therefore making the position-dependent stability lobe diagrams hard to visualise. The modelling process of the vertical mill in order to determine regions of its stable operation for variable position of a headstock is illustrated in Figure 1.

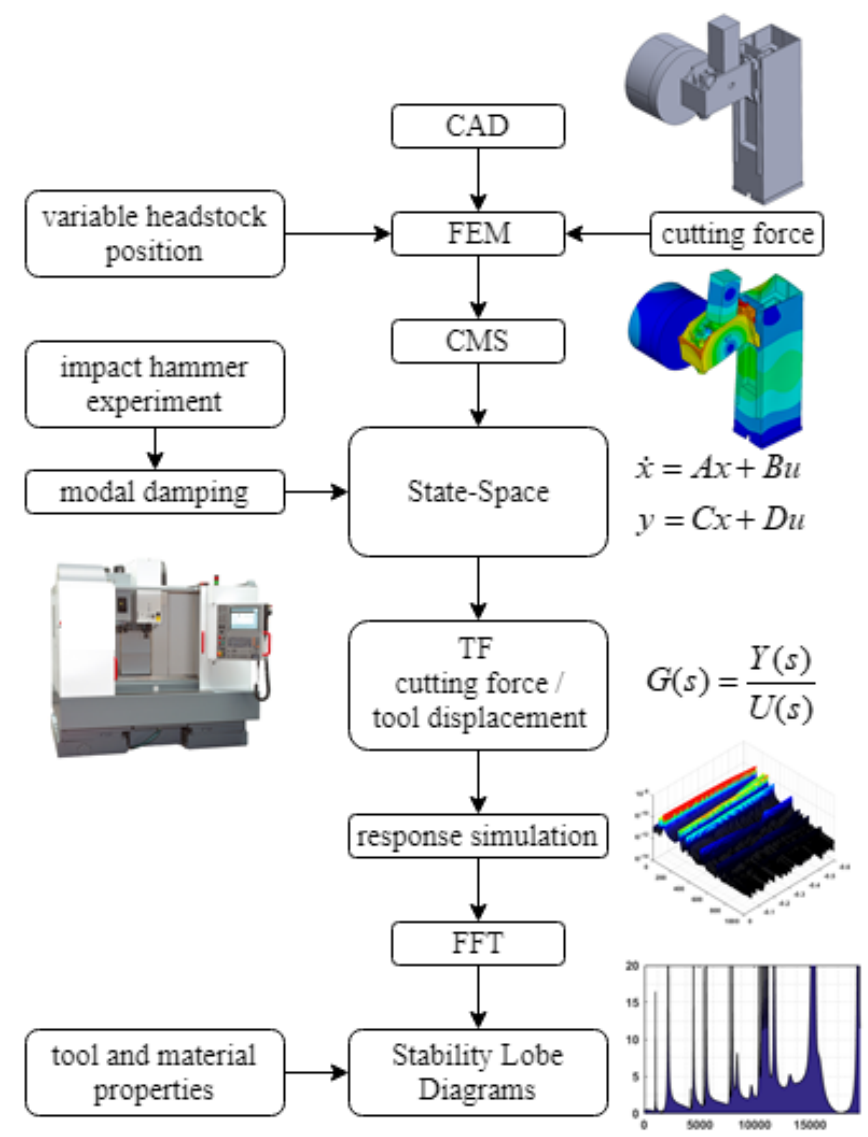

Figure 1: Process of prediction stability lobe diagrams based on a virtual model 
Firstly, CAD model of a selected part of the vertical mill is created, separated into blocks representing key components (i.e. column, headstock, tool magazine, drive, and spindle with tool). Secondly, these components are loaded into Ansys, meshed using conventional solid elements and reduced afterwards via Component Mode Synthesis (CMS) [8], which significantly decreases the number of DOF and speeds up the following analyses. Furthermore, as the machine tool is topologically variable object (e.g. moving parts, change of tools etc.), this technique allows us to adjust each part separately, keeping only joints as master points. The topology of the vertical mill before CMS is applied is shown in Figure 2. Symbols $k$ are used for joint stiffness coefficients, subindexes $X, Y$ and $Z$ correspond with global coordinate system, subindex $R$ corresponds with radial coordinate of the ball bearings.

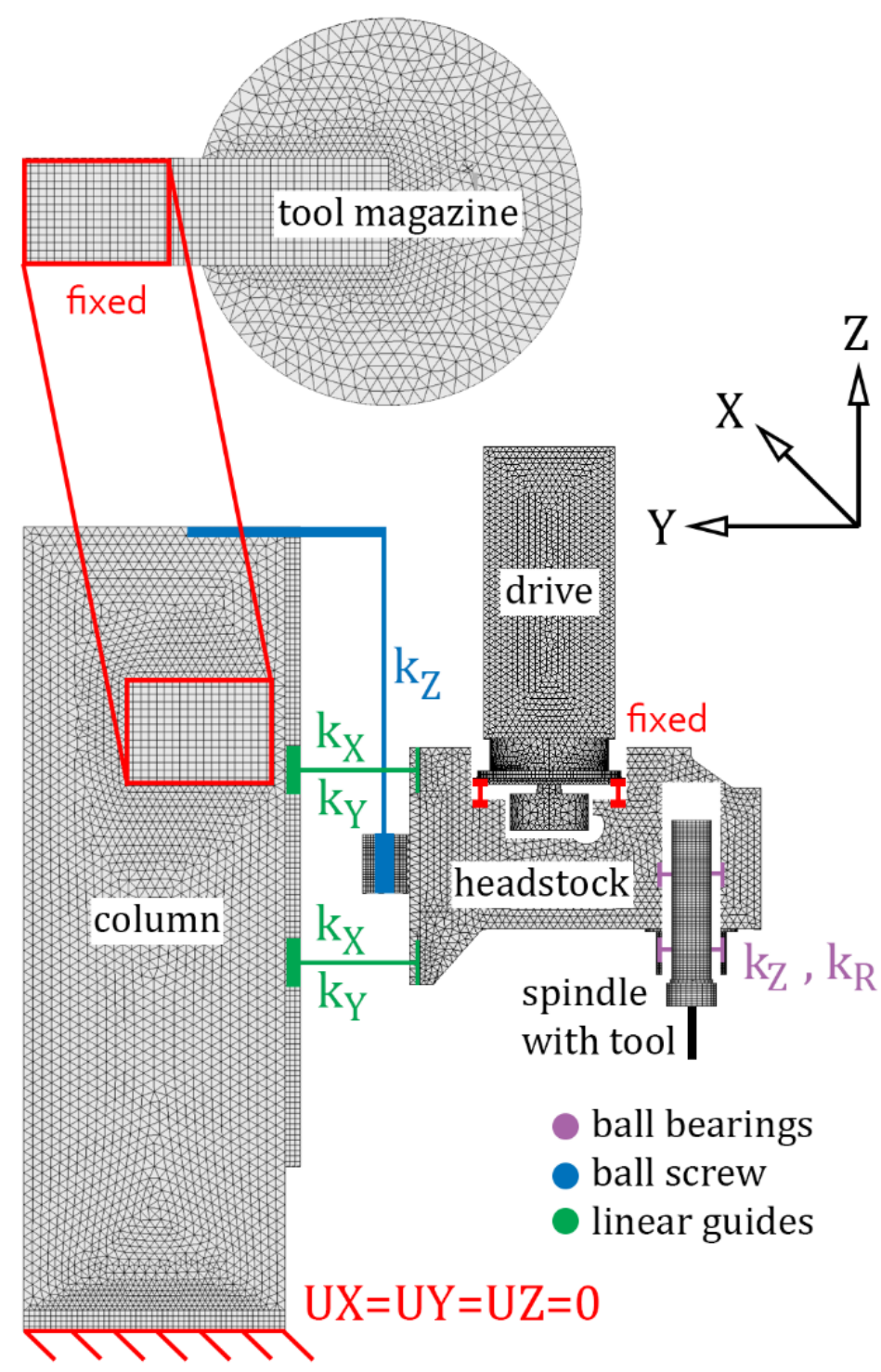

Figure 2: Topology of the vertical mill 
In the next step, a modal analysis is used to transform the model into state-space [9] system for each position of the headstock within its limits. The state-space system consists of 4 state matrices, namely $\boldsymbol{A}, \boldsymbol{B}, \boldsymbol{C}$, and $\boldsymbol{D}$ [10], which contain modal data (i.e. eigenfrequencies, eigenvectors and modal damping) along with information of input and output parameters. The necessity of evaluating dynamic behaviour for multiple positions of headstock is illustrated by the results of modal analyses for variable positions, with only minimal and maximal values of individual eigenfrequencies listed in Table 1. Each mode exhibited these extremes in a different position of the headstock, thus making it difficult to determine a general position (e.g. topmost, bottommost, somewhere in between) where the dynamic stiffness is maximal.

Table 1: Comparison of eigenfrequencies for variable position of the headstock

\begin{tabular}{|r|r|r|r|}
\hline \multirow{2}{*}{$\begin{array}{c}\text { Mode } \\
\text { Number }\end{array}$} & $\begin{array}{c}\text { Minimal } \\
\text { Frequency }\end{array}$ & $\begin{array}{c}\text { Maximal } \\
\text { Frequency }\end{array}$ & Difference \\
\cline { 2 - 4 }$[\mathrm{Hz}]$ & {$[\mathrm{Hz}]$} & {$[\%]$} \\
\hline $\mathbf{7}$ & 98.3 & 111.6 & 13.6 \\
$\mathbf{8}$ & 111.8 & 128.4 & 14.8 \\
$\mathbf{9}$ & 141.3 & 165.4 & 17.1 \\
\hline $\mathbf{1 0}$ & 228.1 & 258.0 & 13.1 \\
\hline $\mathbf{1 4}$ & 461.3 & 521.2 & 13.0 \\
$\mathbf{1 5}$ & 488.5 & 558.2 & 14.3 \\
\hline $\mathbf{1 7}$ & 531.2 & 610.1 & 14.8 \\
\hline
\end{tabular}

As shown in Figure 1, damping is adjusted using experimental data. A time-domain response to impact hammer is measured multiple times, filtered in specific frequency range using Butterworth bandpass filters. These signals were used to determine modal damping for chosen frequency spectra via exponential decay rate. Final values are listed in Table 2.

Table 2: Modal damping for variable frequency spectrums

\begin{tabular}{|c|c|c|c|c|c|}
\hline \multirow{2}{*}{$\begin{array}{c}\text { Frequency } \\
\text { range }\end{array}$} & $\mathbf{1 0 - 5 0}$ & $\mathbf{5 0 - 1 0 0}$ & $\mathbf{1 0 0 - 2 0 0}$ & $\mathbf{2 0 0 - 5 0 0}$ & $\mathbf{5 0 0 - 1 0 0 0}$ \\
\cline { 2 - 6 } & {$[\mathrm{Hz}]$} & {$[\mathrm{Hz}]$} & {$[\mathrm{Hz}]$} & {$[\mathrm{Hz}]$} & {$[\mathrm{Hz}]$} \\
\hline $\begin{array}{c}\text { Modal } \\
\text { damping }\end{array}$ & 0.0203 & 0.0176 & 0.0160 & 0.0128 & 0.0156 \\
\hline
\end{tabular}

\section{Results of response simulations}

Completed virtual model is used to run a series of response simulation to determine positiondependent FRF between cutting force and the displacement of the tool tip. General formula to determine minimal chip width in relation to spindle speed, generally called stability lobe diagram $[6,9]$, is described by the following equation (1)

$$
\boldsymbol{b}_{\text {lim }}=\frac{-1}{2 K_{S} \operatorname{Re}(\boldsymbol{G})}
$$

where $b_{\text {lim }}$ represents limit value of chip width, $K_{s}$ represents cutting stiffness coefficient determined primarily by the material being cut, and $\operatorname{Re}(G)$ is the real part of the FRF between the cutting force and the tool tip displacement. For illustrative purposes, cutting force was 
considered in alignment with global coordinate $X$ and the tool tip displacement only in this coordinate was observed. Using the equation (1), the real part of FRF, cutting stiffness coefficient for stainless steel $K_{S}=2700 \mathrm{Nmm}^{-2}$, and considering a tool with 4 teeth, stability lobe diagrams were constructed for multiple positions of the headstock within $Z$ limits, as illustrated in Figure 3: Position-dependent stability lobe diagrams.

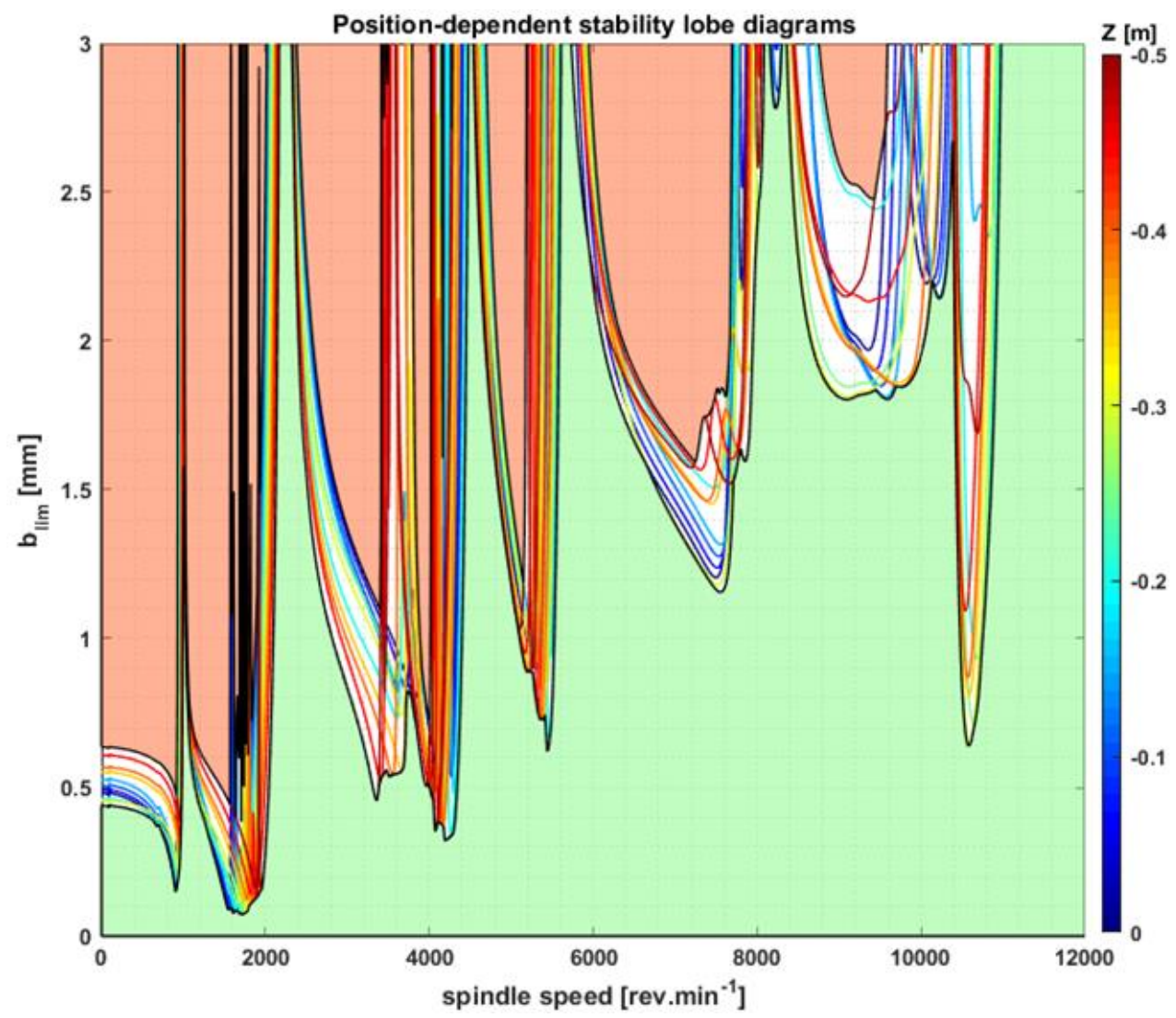

Figure 3: Position-dependent stability lobe diagrams

The diagrams form a zone, in which the behaviour can be either stable or unstable, based on the position of the headstock. The area below the lower envelope (light green colour) is a zone where the behaviour will be always stable regardless on the position. Similarly, the zone above the upper envelope (light red colour) is a zone of unstable behaviour. It can be observed that the position within one of the three coordinates of the machine tool can significantly affect stability of the cutting process. Similar diagrams can be constructed for the remaining two axes of the machine tool, forming a 5-dimensional stability lobe diagram.

\section{Conclusion}

This paper dealt with prediction of unstable behaviour of a machine tool with variable topology. As the presence of unstable vibrations mainly depends on the dynamic stiffness, which changes significantly as the tool moves along the path, the complex structure of a machine tool has to be considered as variable. A methodology based on complex virtual model was proposed and illustrated on an example of a vertical mill. Advanced reduction 
techniques based on CMS and transformation into State-Space models were used to run timeefficient analyses and simulations within time-domain in order to determine FRF between the cutting force and the tool tip displacement. The damping of the machine tool was determined by an experiment and was used to update the virtual model to increase its accuracy. These techniques proved to be very effective and may lead to more accurate prediction of stable operation zones within the work volume of the machine tool.

This work is an output of research and scientific activities of NETME Centre, supported through project NETME CENTRE PLUS (LO1202) by financial means from the Ministry of Education, Youth and Sports „National Sustainability Programme I“, and university research project FSI-S-17-4334.

\section{References}

[1] Z. Hadas, J. Vetiska, J. Juriga, and T. Brezina, MECHATRONIKA, 2012 15th Int. Symp. (2012).

[2] M. Siddhpura and R. Paurobally, Int. J. Mach. Tools Manuf. 61, 27 (2012).

[3] I. Zaghbani and V. Songmene, Int. J. Mach. Tools Manuf. 49, 947 (2009).

[4] Y. Altintas and M. Weck, CIRP Ann. - Manuf. Technol. 53, 619 (2004).

[5] M. Law, Y. Altintas, and A. Srikantha Phani, Int. J. Mach. Tools Manuf. 68, 81 (2013).

[6] T. Brezina, Z. Hadas, and J. Vetiska, Mechatronika, 2012 15th Int. Symp. 1 (2012).

[7] J. Tlusty, Manufacturing Processes and Equipment, 1. (Prentice Hall, Upper Saddle River, 2000).

[8] M. C. C. Bampton and R. R. Craig, Jr., AIAA J. 6, 1313 (1968).

[9] M. R. Hatch, Vibration Simulation Using MATLAB and ANSYS (2001).

[10] Z. Hadas, T. Brezina, O. Andrs, J. Vetiska, and L. Brezina, in 2012 15th Int. Power Electron. Motion Control Conf. (IEEE, 2012), p. LS2e.1-1-LS2e.1-7.

[11] V. Gagnol, B. C. Bouzgarrou, P. Ray, and C. Barra, Int. J. Mach. Tools Manuf. 47, $1176(2007)$. 